\title{
The Effect of Socioeconomic Status and Anomie on Illegal Behavior
}

\author{
Arash Heydari ${ }^{1}$, Ali Teymoori ${ }^{2}$, Behrang Mohamadi ${ }^{1} \&$ Sajad Sarhadi $^{3}$ \\ ${ }^{1}$ School of Sociology, Faculty of Social Sciences, Allame Tabatabaee University, Tehran, Iran \\ ${ }^{2}$ School of Psychology, University of Queensland, Australia \\ ${ }^{3}$ Faculty of Social Sciences, Tehran University, Iran \\ Correspondence: Arash Heydari, School of Sociology, Faculty of Social Sciences, Allame Tabatabaee University, \\ Tehran, Iran. Tel: 98-916-959-1697. E-mail: arash.heydari83@gmail.com
}

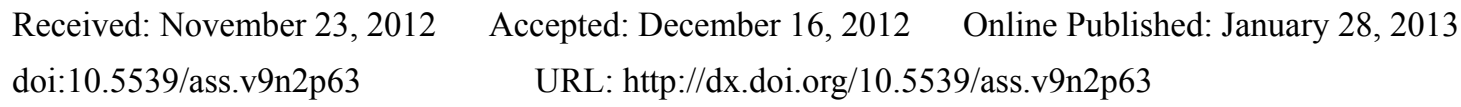

\begin{abstract}
The purpose of the current study is to investigate the relationships between socioeconomic status (SES), feeling of anomie, and law-breaking behavior or illegality. A sample of 480 students has been randomly selected from Shahid Chamran University of Ahvaz in Iran. The results revealed that SES had significant negative correlation with anomie and non-significant correlation with illegality. Anomie had positive correlation with illegal behavior and the fetishism of money dimension had the greatest effect on illegality. The result is discussed with regard to the socio-cultural sphere of Iran as well as with regard to the previous anomie theories including Merton, and Messner and Rosenfeld theories.
\end{abstract}

Keywords: socioeconomic status, anomie, illegal behavior, Iran

\section{Introduction}

Iran is a developing country, and the developing countries are essentially in transition from a traditional society to a modern one and are facing economical, social, and cultural crises. The transition from tradition to modernity, according to a Durkheimian perspective, will lead to an anomic (normlessness and deregulation) status. In this respect, the transition from a former social state to the new one, as it is associated with a weakness in the collective conscience, leads to a weakness in the function of social control over human behavior. Durkheim states that "at the very moment when traditional rules have lost their authority, the richer prize offered these appetites stimulates them and makes them more exigent and impatient of control" (Durkheim, 1951, p. 214).

In the case of Iran, there have been major changes and transformations occurring in the social structure over the last 30 years such as revolution (1979), eight years war (22 September 1980 to 20 August 1988), rapid growth of population (roughly 30 million at 1979- about 70 million at 2009), major structural changes, international sanctions and so on. These changes have many socio-political consequences for Iranian society and drive the society to an anomic situation, and as Durkheim asserted, vast rapid changes can put a society in an anomic condition.

Iranian society has always been involved with the problem of lawbreaking and this phenomenon has been experienced within anomic conditions. Many also believed that anomie is one of the most serious problems of the Iranian community (e.g. Heydari, Teymoori, Nasiri \& Haghish, 2012; Heydari, Teymoori, Nasiri, in press; Heydari, 1389/2010; Kalantari, Rabani \& Sedaghat, 1384/2005; Rafipoor, 1378/1999; Rezaei, 2005, Rezaei \& Ebadollahi, 2006). Since anomie has very bad societal consequences, it is important to investigate what are influential factors on anomie and what are the consequences of it. Thus, we would like to explore how socioeconomic status of individuals, specifically the individuals perception of their social class, influences anomie and how both anomie and subjective socioeconomic status influence the tendency to illegal behavior.

\subsection{Anomie and Illegal Behavior}

According to Durkheim and Merton's anomie theories, anomie can lead to illegality. Durkheim believed that in an anomic society, the regulation of rules and norms are broken or lost their functionality during rapid changes of the society. In fact, anomie weakens the controlling function of the society. In such a society, individuals' demands are infinite, compliance to the rules hardly takes place, and some replaced behaviors like crime and distortions would be inevitable. 
The relation between anomie and illegal behaviors is emphasized by Merton $(1938,1968)$, who has focused on the gap between the cultural goals and institutionalized means which such a gap would lead the society to anomie. When the individual fails to achieve his/her goals by legitimate means, s/he legitimizes using illegal means to get these culturally prescribed goals, and this issue engenders the grounds for the appearance of deviance. Thus, the social structure imposes the force toward deviancy on the individual (Merton, 1968).

Merton believes that the lower classes of the society, due to more limited access to legitimate means to get the cultural goals, are much more predisposed to the feeling of anomie and subsequently to illegal behavior. Some of the studies tested this proposition and showed that individuals of the lower socioeconomic classes are more anomic than middle or upper social classes (Adnanes, 2007; Bell, 1975; Car and Hauser, 1976; Dean, 1961; Heydari et al., 2012; Heydari, Teymoori, \& Nasiri, in press; Heydari, Teymoori, Haghish, Mohamadi, in press; Lee \& Clyed, 1974; Rushing, 1971; Rhodes, 1964; Wilson, 1971). Subsequently, anomie produces a context for illegality.

By using the secondary data, Baumer \& Gustapson (2007) showed that the rate of financial crimes are significantly higher in the arenas in which there is an extreme commitment to financial success whereas there is low commitment to legitimate means; furthermore, lower educational levels and the rate of commitment to financial successes were relevant to financial crimes. Moreover, Menard (1995) found a significant relationship between anomie and delinquency. Winslow (1968) showed that higher levels of crime among the lower social classes of the society are due to the efforts to gain the reward and prestige by relying on illegitimate means. Bordua $(1958$ - 59) showed that the socioeconomic status and anomie are correlated with criminal behavior. In the same vein, Lander (1954) found that both social class and anomie are related to the criminal behavior.

Thus, in the current paper, we are going to look at the relationships between socioeconomic status, anomie, and tendency to illegal behavior simultaneously. Moreover, very serious problems of Iran including anomie, lawbreaking, and illegal behavior are addressed.

\section{Methodology}

\subsection{Participant}

The sample was chosen from university students. Since higher education facilities have widely extended during the last decades and many people from any social classes have been capable of entering universities. Thus, the student sample, especially from governmental public universities which are free of charge or at very low cost and which are also the most valid universities in Iran, has a good distribution both geographically and socioeconomically. There are some quotas for developing cities and areas, where a remarkable number of students from those areas have entered universities as well. Thus, the university sample can be a good representative of Iranian society. Using convenience method of sampling, students from four different faculties of Shahid Chamran University were asked to fill out the self-report questionnaires, they were told that the participation is voluntary and completely anonymous, and after filling the questionnaire, to put their response sheet on a designed box in front of the respective faculty. We had 500 respondents $(\mathrm{M}=21.9, \mathrm{SD}=2.38)$. Twenty of the participants were not scored due to incomplete answers. We had 230 male respondents and 250 female.

\subsection{Instruments}

Multidimensional Scale of Feeling of Anomie. As anomie was a concept with a very high abstraction, it was better captured by assessing it with a multidimensional scale. The multidimensional scale of Feeling of Anomie developed by Heydari, Davoudi and Teymoori (2011) was used which comprises 20 items and three subscales including meaninglessness and distrust dimension ( 8 items), powerlessness subscale ( 7 items), and fetishism of money dimension (5 items) (see appendix 1). The responses were scored from 1 (strongly agree) to 5 (strongly disagree). Alpha coefficients for three subscales are $.79, .72$ and .62 respectively and for the total anomie scale was .82 .

Subjective Socioeconomic Status. In the subjective dimension of socioeconomic status, individuals rate themselves into social classes subjectively. Nabavi, Hosseinzade, and Hosseini's (2009/1387) scale was used to measure the subjective dimension of SES that has 6 items. It assesses individuals' perception of their own social class and evaluates their positions in social structure (appendix 2). Alpha coefficient of this scale in Nabavi et al.'s study was 0.71 .

Tendency to illegal behavior. After reviewing both international and domestic researches around illegality, we determined the indexes which assess the illegal behavior and then some items were made. The items were given to $5 \mathrm{PhD}$ students of sociology and five university lecturers of sociology to determine the validity of the scale 
which they all confirmed the scale is able to capture the tendency to illegal behavior of individuals. The designed variable has 6 items (see appendix 3). The responses were scored from 1 (strongly agree) to 5 (strongly disagree). Alpha coefficient of the scale was .72.

\section{Results}

Descriptive statistics of research variables presented in Table 1. According to Table 1, mean score of feeling of anomie is high (54.11 out of 100). It shows that anomie is an important social problem in Iranian society. Although mean score of anomie was high, the tendency to illegal behavior was less than the average of the total score (11.06 from 30). This could be due to the fact that the sample of the study was students who were more concerned with education and the academic sphere and that can be a barrier for criminal reactions.

Table1. Descriptive statistics of research variables

\begin{tabular}{lllllll}
\hline & Illegality & Anomie & $\begin{array}{l}\text { Subjective } \\
\text { SES }\end{array}$ & Meaninglessness & Powerlessness & $\begin{array}{l}\text { Fetishism } \\
\text { of Money }\end{array}$ \\
\hline Mean & 11.06 & 54.11 & 15.82 & 25.16 & 16.21 & 12.72 \\
Std. D. & 3.60 & 10.01 & 3.72 & 5.68 & 4.34 & 3.32 \\
Skewness & .526 & -.170 & -.290 & .047 & .516 & .254 \\
Minimum & 6.00 & 26.00 & 5 & 9.00 & 8.00 & 6.00 \\
Maximum & 22.00 & 76.00 & 25 & 38.00 & 30.00 & 21.00 \\
\hline
\end{tabular}

As shown in Table 2, the subjective SES does not have significant correlation with illegality. It was found, however, that social class - as an indicator of social structure- has significant correlation with meaninglessness and distrust $\mathrm{r}=-.16$ and $\mathrm{p}<.01$ and powerlessness $\mathrm{r}=-.12, \mathrm{p}<0.01$, but SES does not have significant correlation with fetishism of money. The significant reverse relationship between subjective SES and feeling of anomie was found as well $(\mathrm{r}=-.17, \mathrm{p}<0.01)$.

Table 2. Inter-correlations among research variables

\begin{tabular}{llllll}
\hline & Subjective & anomie & \multicolumn{2}{l}{ Anomie subscales } & \\
\cline { 4 - 6 } & SES & & Meaninglessness & powerlessness & Fetishism of money \\
\hline Illegality & -.03 & $.30^{* *}$ & $.19^{* *}$ & $.20^{* *}$ & $.33^{* *}$ \\
Subjective SES & - & $-.17^{* *}$ & $-.16^{* *}$ & $-.12^{* *}$ & -.08 \\
Anomie & & - & $.81^{* *}$ & $.76^{* *}$ & $.63^{* *}$ \\
Meaningless. & & & - & $.37^{* *}$ & $.26^{* *}$ \\
Powerlessness & & & & - & $.34^{* *}$ \\
\hline
\end{tabular}

**Correlation is significant at 0.01 levels

According to Table 2, the relationship between feeling of anomie and tendency toward illegal behavior is positive and significant $(\mathrm{r}=.30, \mathrm{p}<.01)$ implying that with an increase in feeling of anomie, the tendency toward illegal behavior will increase as well. All anomie subscales have significant relationships with tendency toward illegality which were $.33, .20$ and .19 for fetishism of money, powerlessness, and meaninglessness and distrust respectively.

Finally, three subscales of anomie were entered as an independent variable and illegality was entered as a dependent variable using the stepwise method. Two of the subscales showed significant results (Table 3). In the first model, fetishism of money was loaded as the most efficient variable on illegality, $\mathrm{R}^{2}=.11, \mathrm{~F}(1,478)=59.34$, $\mathrm{p}<.0001$ in which fetishism of money predicted $11 \%$ of the illegality variance and has significant effect on illegal behavior of individuals $\mathrm{B}=.36, \mathrm{SE}=.04, \beta=.33, \mathrm{t}=7.70, \mathrm{p}<.0001$. In the second model, fetishism of money and meaninglessness have significant effects on illegal behavior, $\mathrm{R}^{2}=.12, \mathrm{~F}(2,477)=33.11, \mathrm{p}<.0001$. Not only the combination effect of fetishism of money and meaninglessness was significant $B=5.09, t=6.19, p$ $<.0001$, each variable has unique contribution to the variance of illegal behavior $(\mathrm{B}=.32, \mathrm{SE}=.04, \beta=.30, \mathrm{t}=$ $6.81, \mathrm{p}<.0001$ for fetishism of money and $\mathrm{B}=.07, \mathrm{SE}=.02, \beta=.11, \mathrm{t}=2.49, \mathrm{p}<.05$ for meaninglessness). Results showed that powerlessness does not have a significant causal effect on tendency toward illegal behavior. Fetishism of money has the greatest effect on tendency toward illegality $(\beta=.30)$ followed by meaninglessness and distrust as the next effective factor on illegality $(\beta=.11)$. 
Table 3. Stepwise regression analysis for three anomie subscales and illegality

\begin{tabular}{lllllllll}
\hline & & $\mathbf{R}^{\mathbf{2}}$ & $\mathbf{A d j} . \mathbf{R}^{\mathbf{2}}$ & $\mathbf{B}$ & $\mathbf{S E}$ & $\boldsymbol{\beta}$ & $\mathbf{T}$ & Sig. \\
\hline Step 1: & & .11 & .10 & 6.467 & .617 & & 10.50 & .000 \\
& Fetishism M. & & & .361 & .047 & .332 & 7.704 & .000 \\
Step 2: & & .12 & .11 & 5.097 & .823 & & 6.193 & .000 \\
& Fetishi. M. & & & .329 & .048 & .303 & 6.817 & .000 \\
& Meaninglessn. & & & .070 & .028 & .111 & 2.495 & .013 \\
\hline
\end{tabular}

\section{Discussion}

The current study showed that tendency toward illegality is a consequence of feeling of anomie. The relationship between different dimensions of anomie and illegality clarifies what aspect of the anomie is related to illegal behavior. It was found that fetishism of money plays a major role in anomie and illegality interaction.

Monetary and economical achievement as the criterion of success leads individuals to the notion that "aspirations justify the means". Significant effect of fetishism of money on tendency to illegal behavior is a kind of confirmation of previous theories of anomie especially Merton's (1968) theory. Merton believes that in an anomic society, money is a very important issue in the way that it is accepted not only for its own function as something to exchange but also as a symbol of prestige. He believes that the goal of monetary success is that the society members are flooded by orders and that justifies the right or duty to reach the aspirations even though with frequent frustrations.

Thus, everybody should be rich and this fantasy is endless. Merton asserts that all of the structures that have influence on the formation of personality (e.g. family, school, workplace and so on) come together to help individuals to get monetary and occupational success (p. 76-78). It is a point that is well taken by Messner and Rosenfeld (2001). From Messner and Rosenfeld's view, fetishism of money is a kind of prosperity which emphasized solely on monetary and economical success. They believed the amount of money that determined the status and honor of a person is endless and there is no final stage for the desire and subsequently the financial achievement. To achieve the endless desire for monetary success, the person resorts to any means. The results of the present study confirm the effect of fetishism of money on deviance behavior in general. In addition, the lack of the relation between SES and fetishism of money in the present study implies the equal distribution of the economical aspiration in different social classes which is in harmony with Merton (1968) and Messner and Rosenfeld's (2001) theories.

Another important result was non-significant relation between SES and illegality. By relying on Merton's (1968) theory, it was expected that individuals from low socioeconomic status, due to the inaccessibility of legitimate means for achieving the cultural aspiration to have higher tendency to illegal behavior which is a kind of innovative reaction from Merton's five-mode of adaptations to anomic situation. The result of the current study shows that anomie is an epidemic problem in Iran. However, the low mean of illegality can be justified by the nature of the sample.

In general, socioeconomic status is a major driver of anomic feeling and subsequently anomie is a major influential factor of illegality. Specifically, the fetishism of money dimension of anomie has the highest impact on illegality. Such a change in value system would be so harmful for the collective conscience of the community and would lead not only to illegality but also to other destructive consequences too. To improve the welfare of the society and mind-set of the individuals, this issue should be the main focus of concern. Finally, it is recommended to re-conduct this study in other samples, especially within society not just a student sample, to confirm the generalizability of the results.

\section{References}

Adnanes, M. (2007). Social transitions and anomie among post- communist Bulgarian youth. Young, 15(1), 46-69. http://dx.doi.org/10.1177/1103308807072684

Baumer, E. P., \& Gustafson, R. (2007). Social organization and instrumental crime: Assessing the empirical validity of classic and contemporary anomie theories. Criminology, 45(3), 617-663. http://dx.doi.org/10.1111/j.1745-9125.2007.00090.x

Bell, W. (1957). Anomie, social isolation, and the class structure. Sociometry, 20(2), 105-116. 
http://dx.doi.org/10.2307/2785636

Bordua, D. J. (1958-1959). Juvenile delinquency and "anomie": An attempt at replication. Social Problem, 6(3), 230-238. http://dx.doi.org/10.2307/799077

Cao, L. (2007). Returning to normality: Anomie and crime in China. International Journal of Offender Therapy and Comparative Criminology, 51(1), 40-51. http://dx.doi.org/10.1177/0306624X06294427

Carr, L. G., \& Hauser, W. J. (1976). Anomie and religiosity: An empirical examination. Journal for the Scientific Study of Religion, 15(1), 69-74. http://dx.doi.org/10.2307/1384315

Dean, D. G. (1961). Alienation: Its meaning and measurement. American Sociological Review, 26, 753-758. http://dx.doi.org/10.2307/2090204

Durkheim, E. (1897/1951). Suicide (Simpson, G. Trans. \& Ed.). NY: Free Press.

Heydari, A. (1389/2010). Socioeconomic and cultural factors' role on feeling of anomie among male high school and foundation students of Ahvaz city. Thesis (Master). Shahid Chamran University of Ahvaz, Iran.

Heydari, A., Davoudi, I., \& Teymoori, A. (2011). Revising the assessment of feeling of anomie: Presenting a multidimensional scale. Procedia - Social and Behavioral Sciences, 30, 1086-1090. http://dx.doi.org/10.1016/j.sbspro.2011.10.212

Heydari, A., Teymoori, A., \& Nasiri, H. (in press). Development of suicidality within socioeconomic context: Mediation effect of parental control and anomie. Omega: Journal of Death and Dying.

Heydari, A., Teymoori, A., Haghish, E.F., \& Mohamadi, B. (in press). Influential factors on ethnocentrism: The effect of socioeconomic status, anomie, and authoritarianism. Social Science Information.

Heydari, A., Teymoori, A., Nasiri, H., \& Haghish, E. F. (2012). Relationship between Socioeconomic Status, Anomie, and Authoritarianism. E-Bangi: Journal of Social Sciences and Humanities, 7, 176-188.

Kalantari, S., Rabani, R., \& Sedaghat, K. (1384/2005). The relationship between poverty, law disobedience, and formation of societal problem, (in Persian). Social Welfare Quarterly, 18, 50-74.

Lander, B. (1954). Toward an understanding of juvenile delinquency. NY: Columbia University Press.

Lee, G. R., \& Clyde, R. W. (1974). Religion, socioeconomic status, and anomie. Journal for the Scientific Study of Religion, 13(1), 35-47. http://dx.doi.org/10.2307/1384799

Menard, S. (1995). A developmental test of Mertonian anomie theory. Journal of Research in Crime and Delinquency, 32(2), 136-174. http://dx.doi.org/10.1177/0022427895032002002

Merton, R. K. (1938). Social structure and anomie. American Sociological Review, 3(5), 672-682. http://dx.doi.org/10.2307/2084686

Merton, R. K. (1968). Social theory and social structure. New York: free press.

Messner, S., \& Rosenfeld, S. (2001). Crime and American dream (3th ed.). Belmont, CA: Wadsworth.

Nabavi, S. A., Hosseinzade, H. A., \& Hosseini, S. H. (2009/1987). The effect of socioeconomic status, powerlessness, and ethnic identity on social security. Daneshe Entezami, 10(2), 9-36.

Rafipoor, F. (1378/1999). Anomie: A Study of the Potential for Anomie in Tehran. (Persian) Tehran: Soroush Inc.

Rezaei, M. (1384/2005). Type, amount, and influential factors on law disobedience, (in Persian). Iran Sociological Association, 6(3), 47-69.

Rezaei, M., \& Ebadollahi, H. (1385/2006). Interdisciplinary society: Meta-analysis of law disobedience in Iran, (in Persian). National Studies Quarterly, 27(7), 67-91.

Rhodes, L. (1964). Anomie, aspiration, and status. Social forces, 42(4), 434-440. http://dx.doi.org/10.2307/2574987

Rushing, W. A. (1971). Class, culture and "social structure and anomie". The American Journal of Sociology, 76(5), 857-872. http://dx.doi.org/10.1086/225002

Wilson, R. A. (1971). Anomie in the ghetto: A study of neighborhood type, race, and anomie. The American Journal of Sociology, 7(1), 66-88. http://dx.doi.org/10.1086/225068

Winslow, R. W. (1968). Status management in adolescent social system: A reformulation of Merton's anomie theory. The British Journal of Sociology, 19(2), 143-159. http://dx.doi.org/10.2307/588691 


\section{Appendixes}

Appendix 1. Multidimensional scale of anomie

\section{Meaninglessness and distrust}

I can trust to the statements of high-ranking officials (authority).

There is little use writing to public officials because often they aren't really interested in the problems of average man.

In spite of what some people say, a lot of average man is getting worse, not better.

I believe most of the congress bills are towards the welfare of people.

Most public officials (people in public office) are not really interested in the problems of the average man.

I often wonder what the meaning of life really is.

It's hardly fair to bring children into the world with the way things look for future.

Everything is relative, and there just aren't any definite rules to live by.

\section{Powerlessness}

I lead a trapped or frustrated life.

Nobody knows what is expected of his or her life.

I have no control over my destiny.

The socioeconomic status of people determines their dignity and its inevitable.

The world is changing so fast that it is hard for me to understand what is going on.

My whole world feels like it as falling apart.

No matter how hard people try in life it doesn't make any difference.

\section{Fetishism of money}

To make money, there are no right and wrong ways anymore, only easy ways and hard ways.

A person is justified in doing almost anything if the reward is high enough.

I am getting a college education so I can get a good job.

I follow whatever rules I want to follow.

Money is the most important thing in life.

\section{Appendix 2. Subjective SES scale}

1. How do people evaluate your father's education level? What do you think?

2. How do people evaluate your father's occupational status? What do you think? Participants answer two first items on 5 point Likert continuum: from " $5=$ very valuable", to " $1=$ very worthless".

3. How much does your family's income?

Participants answer this item on 5 point Likert continuum: from " $5=$ very sufficient", to " $1=$ very insufficient".

4. If yours pose housing, how much do you evaluate?

5. If your family doesn't pose housing, how much do you estimate yours parents ability to buy housing?

6. If we divide people into five economical classes, in which class do you consider your family?

Between 4 and 5 items, participant must answer either one that pertains to their situation. They answer to these question from " $5=$ very high", to " $1=$ very low". Response format for item six is as latter continuum.

Appendix 3. Tendency toward illegal behavior scale

Express your tendency toward the following behaviors:

It is true that rules and law are important for the society, but we can neglect and disregard them because of our families and kith and kin. 
Whenever I disregard the law and rules, I can get my work done easier.

In sum, those who have too much commitment to the law are not succeeding in their lives.

Some rules are hard to carry out (are cumbersome) and breaking them is not problematic.

If a policeman was not present, breaking driving rules is not problematic.

I would refuse to pay taxes if I could. 